
UNDER CONTRACT DE-AC02-76CH03073

PPPL-3562

PPPL-3562

UC-70

Non-inductive Current Generation in NSTX using Coaxial Helicity Injection

R. Raman, T.R. Jarboe, D. Mueller, M.J. Schaffer, R. Maqueda, B.A. Nelson,

S. Sabbagh, M. Bell, R. Ewig, E. Fredrickson, D. Gates, J. Hosea, S. Jardin, H. Ji, R. Kaita, S.M. Kaye, H. Kugel, L. Lao, R. Maingi, J. Menard, M. Ono, D. Orvis, F. Paoletti, S. Paul, M. Peng, C.H. Skinner, J.B. Wilgen, S. Zweben, and the NSTX Research Team

May 2001
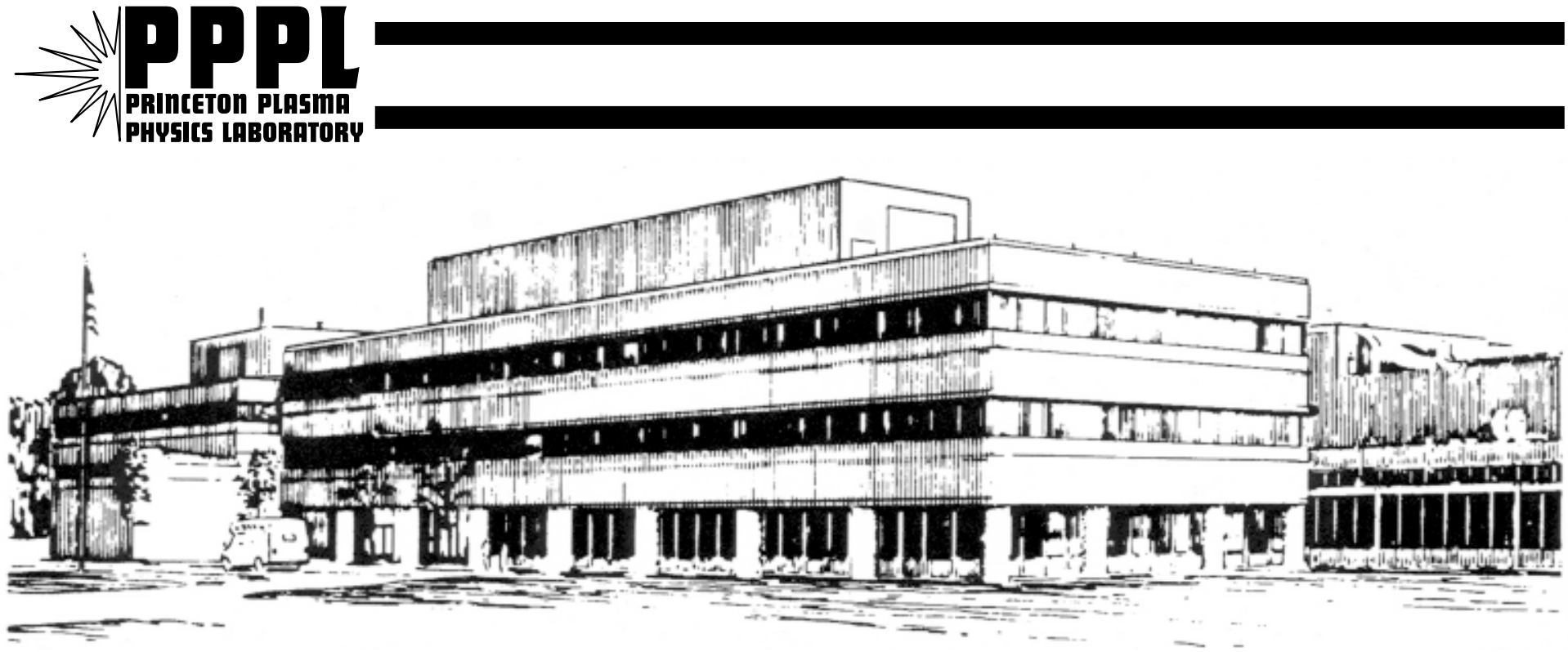

PRINCETON PLASMA PHYSICS LABORATORY PRINCETON UNIVERSITY, PRINCETON, NEW JERSEY 


\section{PPPL Reports Disclaimer}

This report was prepared as an account of work sponsored by an agency of the United States Government. Neither the United States Government nor any agency thereof, nor any of their employees, makes any warranty, express or implied, or assumes any legal liability or responsibility for the accuracy, completeness, or usefulness of any information, apparatus, product, or process disclosed, or represents that its use would not infringe privately owned rights. Reference herein to any specific commercial product, process, or service by trade name, trademark, manufacturer, or otherwise, does not necessarily constitute or imply its endorsement, recommendation, or favoring by the United States Government or any agency thereof. The views and opinions of authors expressed herein do not necessarily state or reflect those of the United States Government or any agency thereof.

\section{Availability}

This report is posted on the U.S. Department of Energy's Princeton Plasma Physics Laboratory Publications and Reports web site in Calendar Year 2001. The home page for PPPL Reports and Publications is: http://www.pppl.gov/pub_report/

DOE and DOE Contractors can obtain copies of this report from:

U.S. Department of Energy

Office of Scientific and Technical Information

DOE Technical Information Services (DTIS)

P.O. Box 62

Oak Ridge, TN 37831

Telephone: (865) 576-8401

Fax: (865) 576-5728

Email: reports@adonis.osti.gov

This report is available to the general public from:

National Technical Information Service

U.S. Department of Commerce

5285 Port Royal Road

Springfield, VA 22161

Telephone: 1-800-553-6847 or

(703) 605-6000

Fax: (703) 321-8547

Internet: http://www.ntis.gov/ordering.htm 


\title{
Non inductive current generation in NSTX using Coaxial Helicity Injection
}

\author{
R. Raman ${ }^{1}$, T.R. Jarboe ${ }^{1}$, D. Mueller ${ }^{2}$, M.J. Schaffer ${ }^{3}$, R. Maqueda ${ }^{4}$, B.A. \\ Nelson $^{1}$, S. Sabbagh ${ }^{5}$, M. Bell ${ }^{2}$, R. Ewig ${ }^{1}$, E. Fredrickson ${ }^{2}$, D. Gates ${ }^{2}$, \\ J. Hosea ${ }^{2}$, S. Jardin ${ }^{2}$, H. Ji², R. Kaita 2 , S.M. Kaye², H. Kugel², L. Lao',

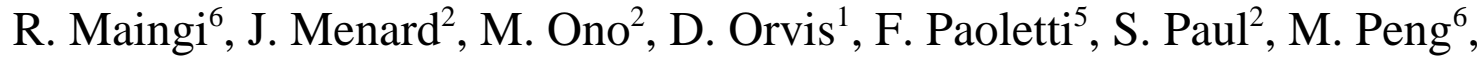 \\ C.H. Skinner ${ }^{2}$, J.B. Wilgen ${ }^{6}$, S. Zweben ${ }^{2}$ and the NSTX Research Team \\ ${ }^{1}$ University of Washington, Seattle, WA, USA \\ ${ }^{2}$ Princeton Plasma Physics Laboratory, Princeton, NJ, USA \\ ${ }^{3}$ General Atomics, San Diego, CA, USA \\ ${ }^{4}$ Los Alamos National Laboratory, Los Alamos, NM, USA \\ ${ }^{5}$ Columbia University, New York, NY, USA \\ ${ }^{6}$ Oak Ridge National Laboratory, Oak Ridge, TN, USA
}

\begin{abstract}
Coaxial Helicity Injection (CHI) on the National Spherical Torus Experiment (NSTX) has produced 240kA of toroidal current without the use of the central solenoid. Values of the current multiplication ratio (CHI produced toroidal current / injector current) up to 10 were obtained, in agreement with predictions. The discharges which lasted for up to $200 \mathrm{~ms}$, limited only by the programmed waveform are more than an order of magnitude longer in duration that any $\mathrm{CHI}$ discharges previously produced in a Spheromak or a Spherical Torus (ST).
\end{abstract}

\section{Introduction}

The Spherical Torus is a magnetic confinement concept that has the advantages of high beta and a projected high fraction of bootstrap current drive. The favorable 
properties of the ST arise from its very small aspect ratio. However, small aspect ratio devices have very restricted space for a substantial solenoid, which restricts the inductive pulse duration. This makes sustained non-inductive operation necessary for the success of the ST concept. Furthermore, entirely removing the central solenoid would simplify the ST design and allow access to the lowest possible aspect ratio. This requires the demonstration of plasma creation without the use of the central solenoid.

Experimental results from the Small Tight Aspect Ratio Tokamak (START) demonstrated some of the favorable high beta properties with good confinement $[1,2]$. This motivated the construction of two large STs, NSTX in the USA $[3,4]$ and the Mega Ampere Spherical Torus (MAST) in the UK [5]. The purpose of NSTX is to demonstrate high beta in conjunction with high bootstrap current drive, plasma generation without the use of the central solenoid and sustained non-inductive operation [3].

Coaxial Helicity Injection $(\mathrm{CHI})$ is a promising candidate for initial plasma generation and for edge current drive during the sustained phase. The first experiments on helicity injection current drive in a ST were conducted on the Current Drive ExperimentUpgrade (CDX-U) at the Princeton Plasma Physics Laboratory (PPPL) [6]. The possibility of using CHI in a ST was first proposed in the late 1980's [7]. The idea gained support as a result of experiments conducted on the Proto-Helicity Injected Torus, and the Helicity Injected Torus - I (HIT-I) at the University of Washington [8]. These experiments used a thick conducting copper wall for equilibrium control of the $\mathrm{CHI}$ produced plasma configuration. These were followed by two other experiments, the 
Himeji Institute of Technology Spherical Torus (HIST) in Japan and the SPHEX device in the UK $[9,10]$. These devices also employed passive wall stabilization for equilibrium control and confirmed that $\mathrm{CHI}$ could be used in the presence of an external toroidal field for the generation of a plasma configuration. Later HIT was rebuilt as the HIT-II experiment, which extended $\mathrm{CHI}$ to a true ST device by employing 28 poloidal field coils for equilibrium control instead of from image currents induced on copper walls [11]. HIT-II produced substantial plasma currents (200kA) using transformer action or using CHI [12]. CHI discharge duration on HIT and HIT-II is typically $10 \mathrm{~ms}$, on HIST it is about $5 \mathrm{~ms}$ and on SPHEX it is about $2 \mathrm{~ms}$.

The CHI method drives current initially on open field lines creating a current density profile that is hollow. Taylor relaxation [13] predicts a flattening of this current profile through a process of magnetic reconnection leading to current being driven throughout the volume, including closed field lines. Current penetration to the interior is eventually needed for usefully coupling $\mathrm{CHI}$ to other current drive methods and to provide $\mathrm{CHI}$ produced sustainment current during the long pulse non-inductive phase.

Section 2 of this paper describes the CHI components on NSTX. Section 3 describes the experimental results. Section 4 is a discussion of the results. The final section is a summary of the results attained thus far.

\section{Implementation of CHI on NSTX}


The nominal NSTX machine parameters are major/minor radius of $0.85 / 0.65 \mathrm{~m}$, elongation $\leq 2.3$, a plasma volume of $12.5 \mathrm{~m}^{3}$ and a machine volume of $30 \mathrm{~m}^{3}$ [3]. The stainless steel vacuum vessel of NSTX is fitted with toroidal ceramic breaks at the top and bottom so that the central column and the inner divertor plates (the inner vessel components) are insulated from the outer wall and the outer divertor plates as shown in Figure 1. Four pairs of Poloidal Field coils (PF2, 3, 4 and 5) placed symmetrically above and below the mid-plane outside the vacuum vessel are available for equilibrium control. The lower divertor region has an additional coil positioned below the inner divertor plate (PF1B). The PF1B and lower PF2 coils allow one to set up the vacuum CHI injector flux in a manner that it connects the lower inner and outer divertor plates as shown in Figure 2a. We refer to the lower gap linked by the poloidal field as the injector and the complementary upper gap as the absorber. These coils allow for the generation of up to $500 \mathrm{mWb}$ of injector flux. The injector flux is defined as $\int \mathrm{B}_{\text {poloidal }} \bullet \mathrm{dS}$, where the surface of integration is over the entire center stack and inner divertor plates (the inner vessel components). The corresponding maximum toroidal flux (TF) for a nominal $0.3 \mathrm{~T}$ discharge is $1.5 \mathrm{~Wb}$ which is that enclosed within the region surrounded by the plasma facing components.

CHI is implemented on NSTX by driving current along field lines that connect the inner and outer lower divertor plates. The poloidal field connecting the lower inner and outer divertor plates is shown by the loop in Figure $2 \mathrm{a}$. A $50 \mathrm{kA}, 1 \mathrm{kV}$ DC power supply is connected across the inner and outer vessel components, to drive the injector current. The standard operating condition for CHI in NSTX uses the inner vessel and inner divertor 
plates as the cathode while the outer divertor plates and vessel is the anode. A dedicated gas injection system in the lower divertor region injects gas from four ports in the lower inner divertor plates, each toroidally separated by 90 degrees. For the initial $\mathrm{CHI}$ operations, four fixed volume plenums were filled to a known pressure and quickly emptied into the divertor region by opening four fast valves each connecting a plenum to a port in the inner lower divertor plates. The initial puff transiently produces a high gas pressure in the lower divertor region. This facilitates gas breakdown when voltage is applied to the lower divertor plates. An $18 \mathrm{GHz}, 10 \mathrm{~kW}$ Electron Cyclotron Heating PreIonization system (ECH-PI) is used to produce a vertical EC resonance layer near the center stack (at a radius of $40 \mathrm{~cm}$ ). The EC resonance layer intersects the inboard injector flux footprints, facilitating gas breakdown.

\section{Experimental results}

The operational procedure involves first energizing the TF coils and the CHI injector coils to produce the desired flux conditions in the injector region. A voltage is then applied to the inner and outer divertor plates and a pre-programmed amount of gas is injected from the inner lower divertor plate ports. These conditions cause the gas in the lower divertor region to ionize and result in current flowing along helical magnetic field lines connecting the lower divertor plates. The ratio of the applied toroidal field to the poloidal field causes the current in the plasma to develop a strong toroidal component, the beginning of the desired toroidal plasma current. If the injector current exceeds a threshold value, the resulting $\Delta \mathrm{B}_{\text {tor }}{ }^{2},\left(\mathbf{J}_{\text {pol }} \times \mathbf{B}_{\text {tor }}\right)$, stress across the current layer exceeds 
the field line tension of the injector flux causing the helicity and plasma in the lower divertor region to move into the main torus chamber. Once extended into the vessel, currents need to be driven in the PF coils for equilibrium position control.

That this method works on a large ST is shown in Figure $2 \mathrm{~b}$. Figure $2 \mathrm{~b}$ shows a $\mathrm{CHI}$ discharge evolution as recorded by a fast framing camera [14]. These fish eye view images of the entire NSTX vessel show that at $\mathrm{t}=16 \mathrm{~ms}$, the discharge originates in the lower divertor region. As the injector current increases, the flux lines connecting the lower divertor plates are extended into the confinement chamber (at $t=18 \mathrm{~ms}$ ). In this early discharge on NSTX, a peak toroidal current of 20kA was obtained for an injector current of about $7 \mathrm{kA}$ resulting in a current multiplication factor of about 3 . The injector current is the current supplied by the $1 \mathrm{kV} \mathrm{CHI}$ power supply that flows through the plasma load. The toroidal current is that measured by the NSTX plasma current measurement system.

Figure 3 shows the applied injector voltage, injector flux, injector current and CHI produced toroidal current, for a high current discharge. The applied CHI injector voltage determines the amount of injector current that can be driven for this combination of toroidal field, injector flux and divertor gas pressure.

The discharges shown in Fig. 3 were produced in a so called "wide footprint" configuration in which the injector field line intersections with the divertor plates are spread far apart, as seen in Figure 4a, which shows contours of the vacuum poloidal flux 
for a similar discharge. While this configuration produced high toroidal current ramp rates and final current levels, it is unlikely to lead to current reconnection and the production of closed poloidal flux. Figure $4 \mathrm{c}$ shows the vacuum flux contours for the alternative "narrow flux footprint" configuration in which the field lines intersect the plates closer together, as they would be during normal single-null inductive discharges.

In Figure 5, we show the CHI discharge corresponding to the case in Figure 4. For this case we have replaced the injector flux with the current in the lower PF3 coil to show the imposed current ramp on this coil. In addition to these changes, the magnitude of the vertical field is increased to push the plasma away from the outer vessel wall.

\section{Discussion}

This discharge shown in Figure 3 has two phases. For times less than 50ms (phase 1), the applied voltage and the divertor coil currents are constant. This results in an injector current of 22kA and a toroidal current of 50kA (a current multiplication factor of 2). To increase the current multiplication factor, the divertor coil current is ramped down during phase $2(t>50 \mathrm{~ms})$. This results in reduced injector flux and consequently the injector impedance increases due to the increased path length. To compensate, the injector voltage is increased as shown in Figure 3. The programmed voltage ramp causes a small increase in the injector current. Since the injector flux is decreasing with time, while the toroidal flux is constant, for reasons described later one expects the current multiplication factor to increase. Indeed, the toroidal current increased during the course 
of the discharge, resulting in a maximum of about 200kA at $\mathrm{t}=150 \mathrm{~ms}$, a current multiplication factor of 7 . The discharge for its entire duration was maintained in equilibrium using pre-programmed coil currents only. From $t=150$ to $200 \mathrm{~ms}$, currents in all the PF coils are held constant. This results in a current flattop duration of 50ms. The discharge was intentionally terminated at the end of $200 \mathrm{~ms}$.

The configuration shown in Figure $4 \mathrm{c}$ was considered more likely to lead to closed flux and would be the preferred configuration for coupling $\mathrm{CHI}$ to inductive discharges. However, while it was found that quite high values of the current multiplication factor could be obtained with the narrow footprint, unambiguous evidence for flux closure during CHI has not yet been obtained in NSTX. Establishment of closed flux requires the capability to reconstruct the flux surfaces using an equilibrium fitting code that includes capability for current on open field lines and in the private flux region. This code work is currently under development. Furthermore, discharges in this configuration frequently terminate in an absorber arc.

An absorber arc is a condition in which the insulator in this region is electrically shorted by a localized plasma forming in the region. Electrical shorting can easily be induced by an expanding $\mathrm{CHI}$ plasma, that because of inadequate vertical position control contacts the divertor plates in the absorber end of the machine. Absorber shorting can also occur due to a combination of field line length and neutral density in this region that satisfies a Paschen condition for gas breakdown. Under conditions of absorber arcing, the CHI power supply current will no longer flow through the plasma load as the discharge 
through the absorber arc has much lower impedance. The injector current will then flow up along the outer vessel components, connect to the center stack at the absorber and return down along the center stack. Such a discharge has the potential to damage the absorber insulator because of localized energy deposition. The $\mathrm{CHI}$ operation procedure on NSTX therefore tries to avoid this condition. Safety systems are in place to minimize the energy deposition to the absorber during such an occurrence and to rapidly shut off the CHI power supply.

The probability of absorber arcs can be minimized through control of the magnetic field pattern in the absorber region as is routinely done on the HIT-II experiment. Present NSTX hardware does not have this capability. Therefore, we have developed a method for attaining the "narrow flux footprint" configuration in a controlled manner. In this method we start with the wide footprint case as shown in Figure 4a. On time scales of $50 \mathrm{~ms}$ as the toroidal current builds up and extends into the vessel, we energize the PF coils in the absorber region to control the extent of vertical plasma growth. This can be seen by the modification to the vacuum flux pattern for cases (a) and (b) in Figure 4. There is increased current flowing in the top PF coils. Simultaneously during the time period of 100 to $200 \mathrm{~ms}$ we decrease the current in the lower PF3 coil to produce the narrow footprint condition. In Figure 4a, the lower PF3 coil has $+1500 \mathrm{~A}$ in it at $50 \mathrm{~ms}$ while in Figure 4c, the current in the same coil has been reduced to $-300 \mathrm{~A}$ at $160 \mathrm{~ms}$. 
The dramatic effect of these modified coil wave forms is seen from the fast camera images for the shots shown in Figures 3 and 5. The configuration shown in Figure 5 is much less extended into the vessel because of the larger currents driven in the top PF coils. This can be noted by examining the differences in the density of the flux surfaces near the PF coils in Figure 4a and 4c. The other observation is that the flux footprints as shown by the curvature of the bright regions in the camera image which correspond to the location of the open field line region are closer together and shows features generally seen in single null Ohmic discharges. The dark region inside of the brighter edge regions could correspond to the location of closed flux plasma.

We define a "poloidal flux utilization factor", $\varepsilon_{\Psi}=\left(I_{\text {toroidal }} / \Psi_{\text {toroidal }}\right)\left(\Psi_{i n j} / I_{i n j}\right)$, where $I_{\text {toroidal }}$ and $\Psi_{\text {toroidal }}$ are the total toroidal current and toroidal flux in the confinement region, and $I_{i n j}$ and $\Psi_{i n j}$ are the total poloidal current and poloidal flux of the injector. For the model of constant $\lambda_{i n j}=\mu_{o} I_{i n j} / \Psi_{i n j}[13], \varepsilon_{\Psi}$ will approach the value 1 when the injector flux fully fills the confinement region [15]. For the shot shown in Figure 3, Figure 6 shows the value of $I_{i n j} *\left(\Psi_{\text {toroidal }} / \Psi_{i n j}\right)$ compared to the measured $I_{\text {toroidal }}$. This analysis shows that within uncertainties, the poloidal flux utilization factor is nearly 1 at $\mathrm{t}=150$ to $200 \mathrm{~ms}$. The measured $I_{\text {toroidal }}$ is lower during the early part of the discharge as only a small portion of the total toroidal flux $(1.5 \mathrm{~Wb})$ is linked by the injector flux.

In these discharge the amount of gas puffed resulted in a vessel pressure of $200 \mathrm{mPa}$. These pressures may seem to be high for conventional tokamak operation. However, NSTX has recently produced 600kA Ohmic discharges in which the edge 
pressures reached $130 \mathrm{mPa}$. These results in addition to other $\mathrm{CHI}$ discharges at vessel pressures of $130 \mathrm{mPa}$ mean that the low gas density requirement for Ohmic discharge compatibility has been satisfied on NSTX.

\section{Summary}

Initial CHI experiments on NSTX have successfully generated 240kA of toroidal current using about $25 \mathrm{kA}$ of injector current. The factor of 10 in current multiplication is in agreement with the design values. Stable discharges lasting for $200 \mathrm{~ms}$ have been produced using pre-programmed coil currents and at vessel neutral densities compatible with high recycling divertor operation and Ohmic operation. The CHI discharge duration obtained on NSTX is more than an order of magnitude longer than previously attained by CHI in a spheromak device or an ST.

Acknowledgements: Pioneering work on smaller experiments that motivated this large scale experiment on NSTX were first conducted by Thomas R. Jarboe at the University of Washington and by Masa Ono at the Princeton Plasma Physics Laboratory. This work is supported by U.S. DOE contract numbers. DE-AC02-76CH03073, DE-AC0500R22725, DE-AC03-99ER54463, DE-FG02-99ER54524, DE-FG03-99ER54519, W7405-ENG-36. 


\section{References:}

[1] Sykes, A., et al., Phys. Rev. Lett. 84 (2000) 495.

[2] Gates, D., et al., Phys. Plasmas 5 (1998) 1775.

[3] Ono, M., et al., Nucl. Fusion 40, 3Y (2000) 557.

[4] Kaye, S., et al., Fusion Technol. 36 (1999) 16.

[5] Darke, A.C., Fusion Engineering 2 (1995) 1456.

[6] Ono, M., et al., Phys. Rev. Lett. 44, (1980) 393.

[7] Jarboe, T.R., Fusion Tech. 15, (1989) 7.

[8] Nelson, B.A., et al., Phys. Plasmas 2 (1995) 2337.

[9] Nagata, M., et al., 17th IAEA Fusion Energy Conference, Yokohama, IAEA-CN 69/EXP4/10 (1998).

[10] Browning, P.K., et al., Phys. Rev. Lett. 68 (1992) 1722.

[11] Jarboe, T. R., et al., Phys. Plasmas 5, (1998) 1807.

[12] Jarboe, T.R., et al, 17th IAEA Fusion Energy Conference, Yokohama, IAEA-CN 69/PDP/02 (1998).

[13] Taylor, J.B., Rev. Mod. Phys. 28, (1986) 243.

[14] Maqueda, R.J. and Wurden, G.A., Nucl. Fusion 39 (1999) 629.

[15] Barnes, C.W., et al., Phys. Fluids 29 (1986) 3415.

E-mail address of R. Raman: raman@aa.washington.edu

\section{Figure Captions}

Figure 1: NSTX machine layout 
Figure 2: (a) Pictorial representation of CHI in NSTX (b) Fish eye camera images of an early CHI discharge in NSTX. The discharge originates in the lower divertor region and extends into the vessel.

Figure 3: 200kA discharge sustained for $200 \mathrm{~ms}$ and fast camera fish eye image of the discharge at $\mathrm{t}=138 \mathrm{~ms}$.

Figure 4: Vacuum flux plots (for SN 102579) show the differences between the wide foot print and narrow flux footprint cases on NSTX and the transition from first to the later case. The separation between contours is $20 \mathrm{mWb}$.

Figure 5: 240kA discharge with a factor of 10 current multiplication obtained in a nearly optimized flux configuration and fast camera fish eye image at $t=146 \mathrm{~ms}$. The current in the PF3 coil is the current per turn. There are 30 turns in the PF3 coil.

Figure 6: Measured and calculated ( $\left.\mathrm{I}_{\text {toroidal }}=\left(\Psi_{\text {toroidal }} / \Psi_{\text {inj }}\right) * I_{\text {inj }}\right)$ toroidal currents shows that the measured current approaches $100 \%$ of the maximum possible current. 


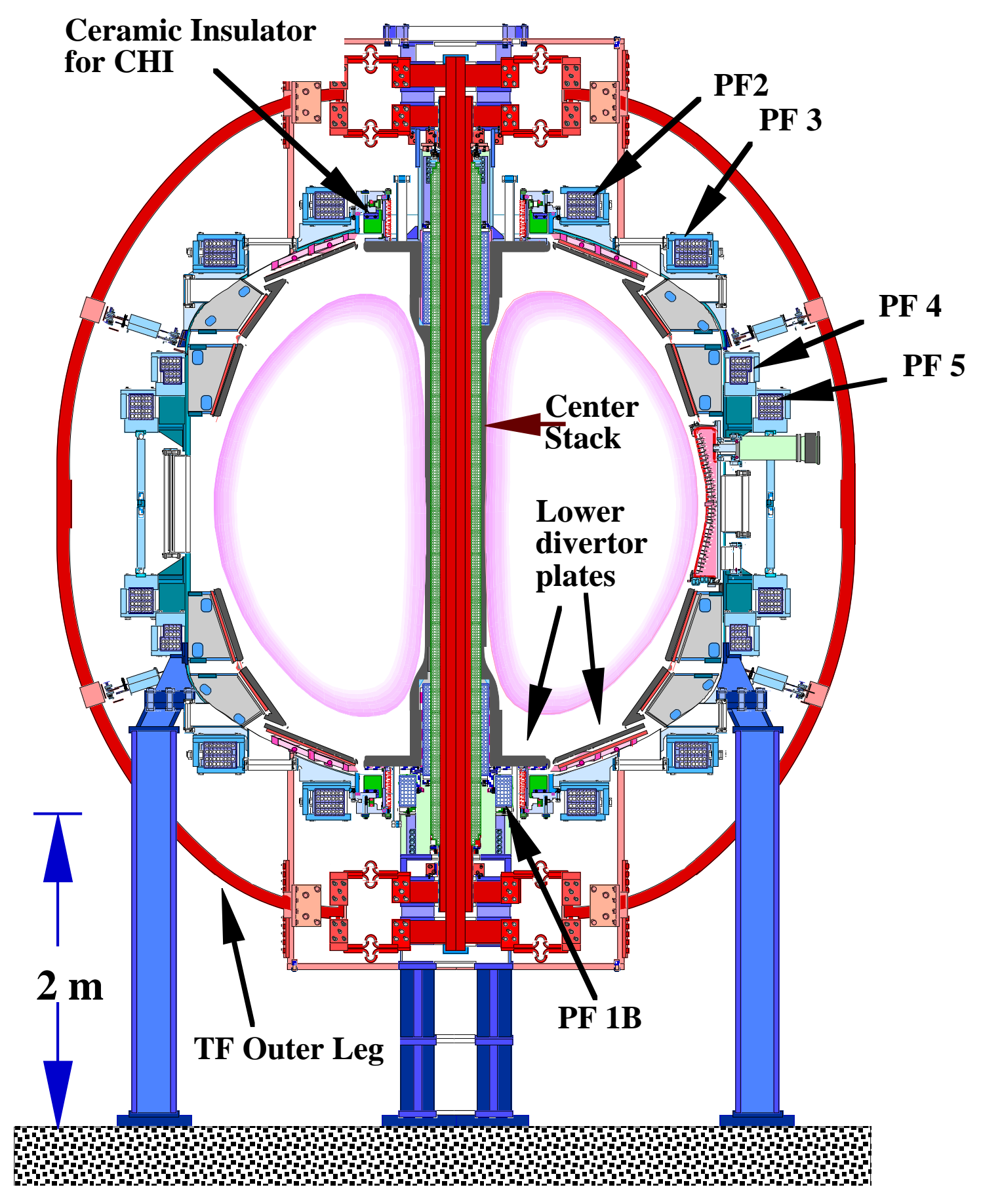



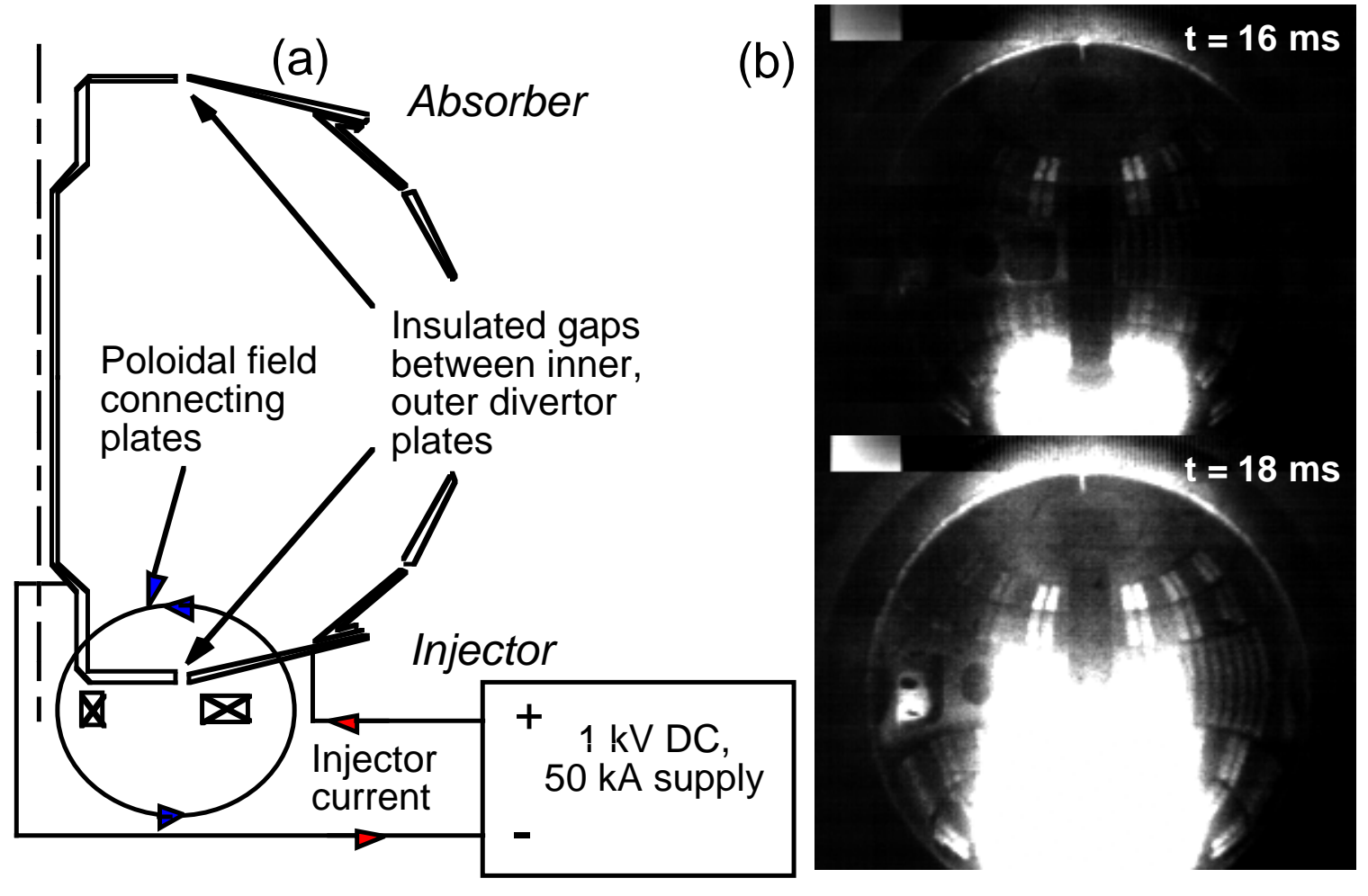

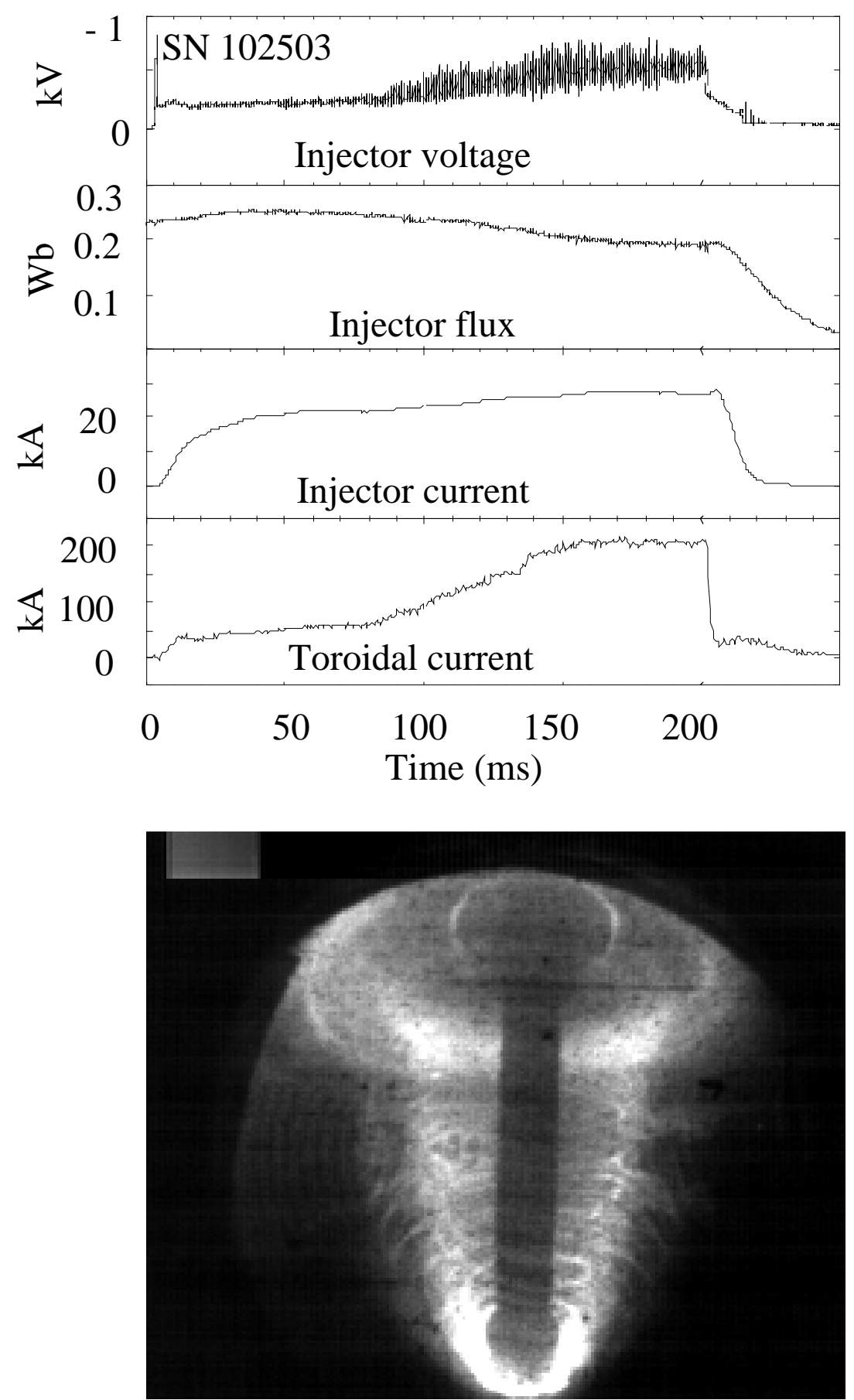


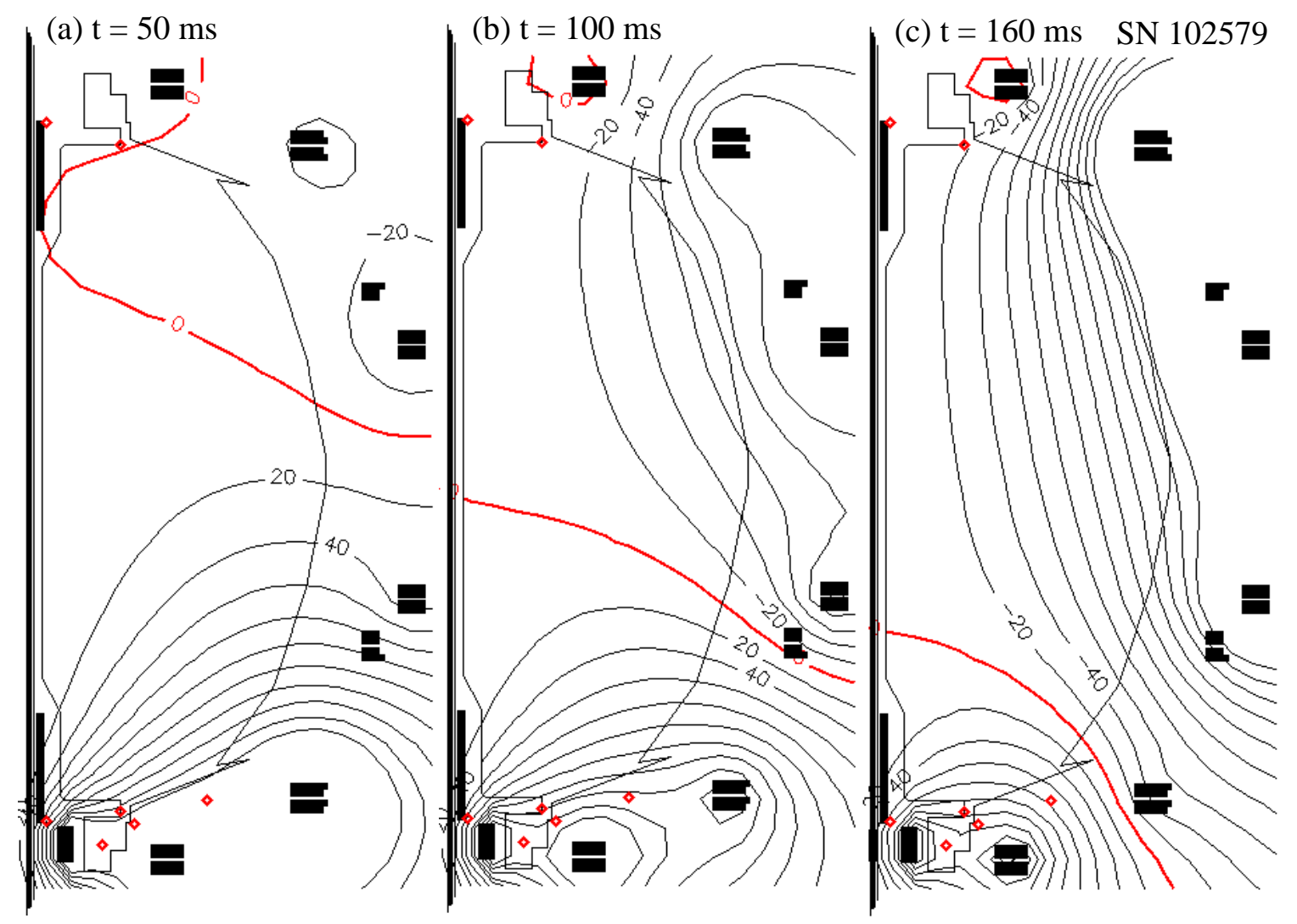



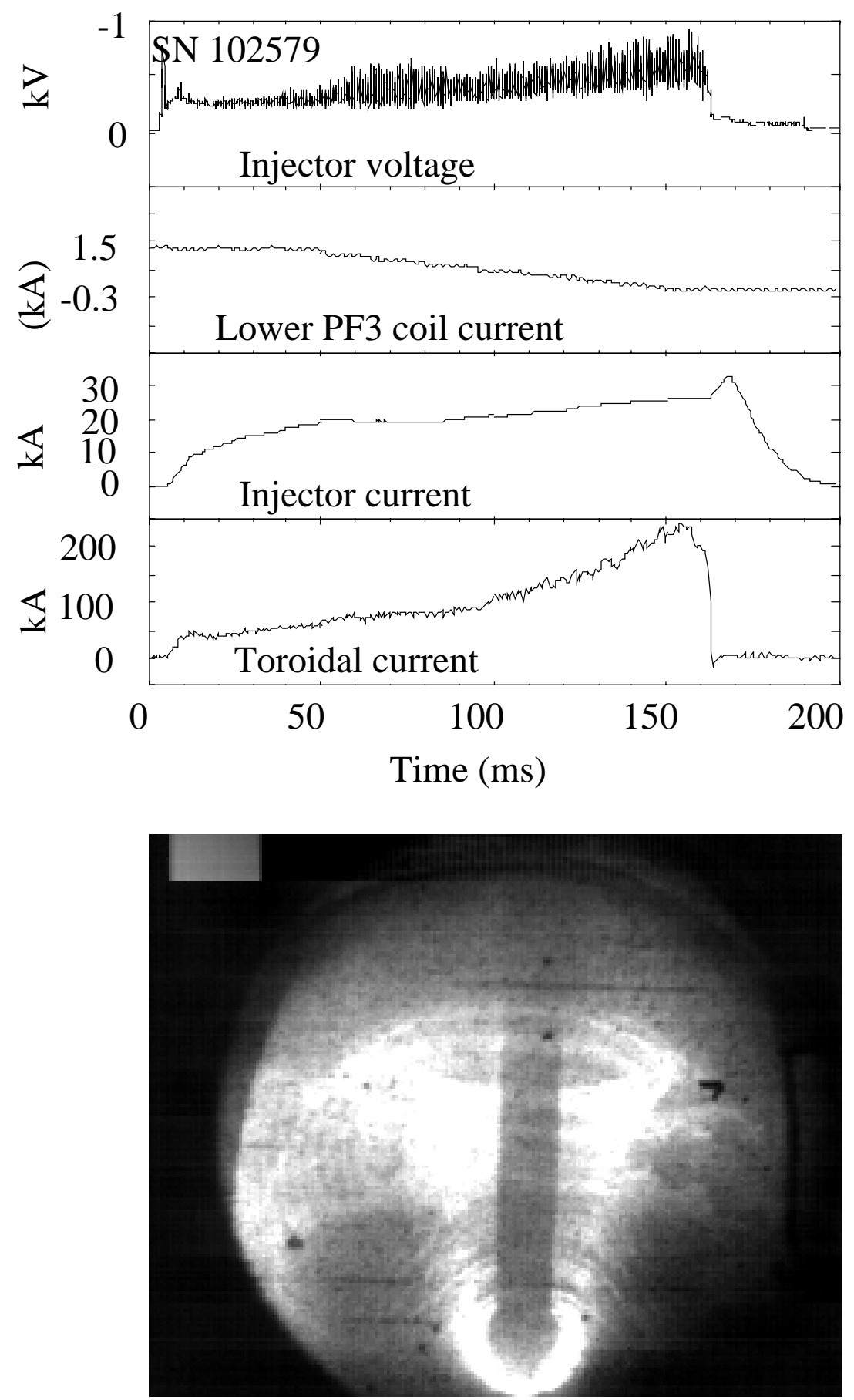


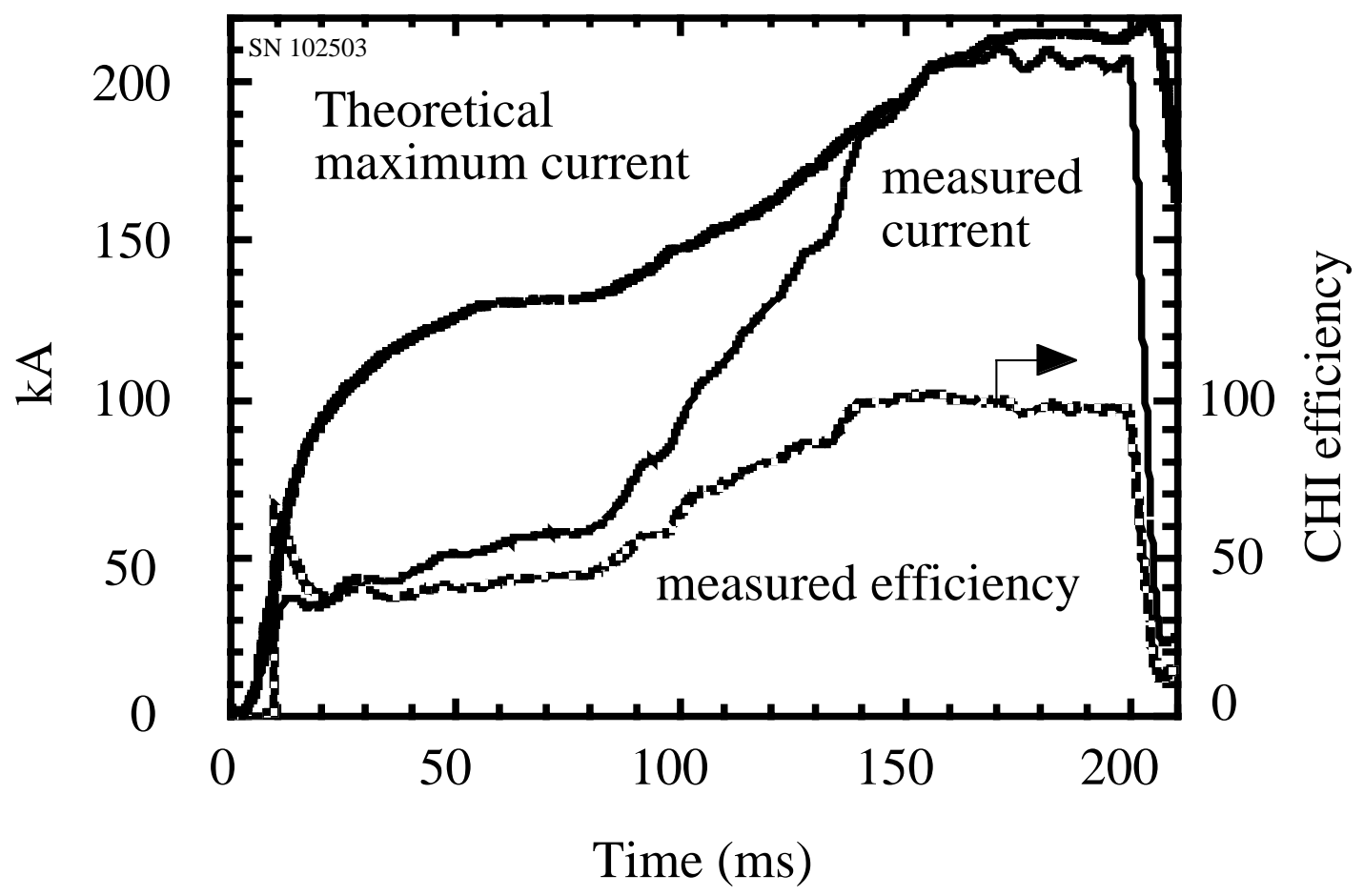




\section{External Distribution}

Plasma Research Laboratory, Australian National University, Australia

Professor I.R. J ones, Flinders University, Australia

Professor J oão Canalle, Instituto de Fisica DEQ/IF - UERJ , Brazil

Mr. Gerson O. Ludwig, Instituto Nacional de Pesquisas, Brazil

Dr. P.H. Sakanaka, Instituto Fisica, Brazil

The Librarian, Culham Laboratory, England

Library, R61, Rutherford Appleton Laboratory, England

Mrs. S.A. Hutchinson, JET Library, England

Professor M.N. Bussac, Ecole Polytechnique, France

Librarian, Max-Planck-Institut für Plasmaphysik, Germany

J olan Moldvai, Reports Library, MTA KFKI-ATKI, Hungary

Dr. P. Kaw, Institute for Plasma Research, India

Ms. P.J . Pathak, Librarian, Insitute for Plasma Research, India

Ms. Clelia De Palo, Associazione EURATOM-ENEA, I taly

Dr. G. Grosso, Instituto di Fisica del Plasma, Italy

Librarian, Naka Fusion Research Establishment, J AERI, J apan

Library, Plasma Physics Laboratory, Kyoto University, J apan

Research Information Center, National Institute for Fusion Science, J apan

Dr. O. Mitarai, Kyushu Tokai University, J apan

Library, Academia Sinica, Institute of Plasma Physics, People's Republic of China

Shih-Tung Tsai, Institute of Physics, Chinese Academy of Sciences, People's Republic of China

Dr. S. Mirnov, TRINITI, Troitsk, Russian Federation, Russia

Dr. V.S. Strelkov, Kurchatov Institute, Russian Federation, Russia

Professor Peter Lukac, Katedra Fyziky Plazmy MFF UK, Mlynska dolina F-2, Komenskeho Univerzita, SK-842 15 Bratislava, Slovakia

Dr. G.S. Lee, Korea Basic Science Institute, South Korea

Mr. Dennis Bruggink, Fusion Library, University of Wisconsin, USA

Institute for Plasma Research, University of Maryland, USA

Librarian, Fusion Energy Division, Oak Ridge National Laboratory, USA

Librarian, Institute of Fusion Studies, University of Texas, USA

Librarian, Magnetic Fusion Program, Lawrence Livermore National Laboratory, USA

Library, General Atomics, USA

Plasma Physics Group, Fusion Energy Research Program, University of California at San Diego, USA

Plasma Physics Library, Columbia University, USA

Alkesh Punjabi, Center for Fusion Research and Training, Hampton University, USA

Dr. W.M. Stacey, Fusion Research Center, Georgia Institute of Technology, USA

Dr. J ohn Willis, U.S. Department of Energy, Office of Fusion Energy Sciences, USA

Mr. Paul H. Wright, Indianapolis, Indiana, USA 
The Princeton Plasma Physics Laboratory is operated by Princeton University under contract with the U.S. Department of Energy.

\author{
Information Services \\ Princeton Plasma Physics Laboratory \\ P.O. Box 451 \\ Princeton, NJ 08543
}

Phone: 609-243-2750

Fax: 609-243-2751

e-mail: pppl_info@pppl.gov

Internet Address: http://www.pppl.gov 